\title{
Urgences
}

\section{Conditions du contrat}

\section{Michel Savard}

Numéro 6, 4e trimestre 1982

URI : https://id.erudit.org/iderudit/025094ar

DOI : https://doi.org/10.7202/025094ar

Aller au sommaire du numéro

Éditeur(s)

Urgences

ISSN

0226-9554 (imprimé)

1927-3924 (numérique)

Découvrir la revue

Citer ce document

Savard, M. (1982). Conditions du contrat. Urgences, (6), 71-84.

https://doi.org/10.7202/025094ar

Ce document est protégé par la loi sur le droit d'auteur. L'utilisation des services d'Érudit (y compris la reproduction) est assujettie à sa politique d'utilisation que vous pouvez consulter en ligne.

https://apropos.erudit.org/fr/usagers/politique-dutilisation/
Cet article est diffusé et préservé par Érudit.

Érudit est un consortium interuniversitaire sans but lucratif composé de l’Université de Montréal, l'Université Laval et l'Université du Québec à Montréal. Il a pour mission la promotion et la valorisation de la recherche. https://www.erudit.org/fr/ 
MICHEL SAVARD

Conditions du contrat 
1. ce billet vendu sous réserve

matin de mal-éveil

nuages en couettes l'automobile

rattrape le rapide quelques flâneurs

le quai leur donne l'aire d'aller

et venir à leur guise

près des guichets sous les lèvres

la joue tiède et duvetée de mère

si vite étreinte la dernière minute

à peine temps d'y être que

les quelques marches

trois ou quatre

mains qui baillent 
2. ce billet ne sera honoré qu'au jour

rase campagne

routes rurales

silos de métal

villages en rangs

et pourtant il tourne

ce monde sous roues

les arbres à témoins 
3. valide sauf stipulation contraire

saint-pascal station

racines maternelles agriffées

aux failles des granits millénaires

racines de lichen rongeuses

de dos de baleines de blocs

erratiques

la précipitation

des enfants en quête d'accidents

et l'indéracinable des rabougris

tenaces d'épinettes

l'autre échelle 


\section{4. ne pas être détaché sans quoi}

les saisons

bel exemple de fidélité

sont précises à suivre leur enchâssement

jusqu'à terme dans l'aine des labours

les oies blanches de retour

cancanent

la locomotive souligne

de longs cris l'envergure

soulevant des voiliers disloqués

devant le soleil

j'imagine une terre antérieure

qu'ils assombrissaient

des jours durant 
5. le prix des places réservées

croisement des convois

vacarme des containers à répétition

de ce qu'ils contiennent dans le noir

citernes voitures japonaises empilées

plates-formes et wagons réfrigérés

I'enfant chahute d'ennui

le chef du train vient s'assurer

que tout va bien son père

est engagé dans une discussion

il n'a qu'à hausser le ton

"dominique" I'enfant fuit

il suit ce camion rouge

sur l'autoroute

quelques arbres tordus

disons "chigner" 
6. aux tarifs de groupe

I'animal est grégaire

le signalent à distance les flèches

de ses temples leurs carillons

publiant naissances fusions

et redditions à la terre

sur les champs noyés

distinguer plein ouest

une ville sur sa falaise de rive

flancs exposés flancs

prêtés jadis

I'analyse ne cesse de sonder

l'entropie de la mémoire

et les enfants récitent

I'alphabet anglais 
7. le passage peut être refusé

des voyageurs à l'arrêt

cèdent à d'autres leurs places

sur les cordes les vêtements

oscillent mollement

les wagons craquent

que la locomotive étire

et I'aiguillage claque

"sur le pont d'avignon"

chantent les enfants puis se plaignent

de la longueur du trajet

saint-apollinaire

petit cimetière 
8. avec une diligence raisonnable

les quenouilles s'échiffent au pied des tiges les fossés débordent le soleil à petit feu gruge plaines et plaines de neige faisant de-ci de-là saillir de longues courroies de terre

s'ils sont sages les enfants dormiront leurs parents leur donneront le droit de regarder le match à la télévision 


\section{9. le transporteur peut être remplacé}

sa vue faiblit on dit

qu'il ne peint plus que sa science des couleurs

il cherche l'honnête homme du dix-neuvième siècle au jour de l'allée questionnant humblement des inconnus s'ils pressentent comme lui l'extinction des feux sous l'abondance

les prairies développent

leur prose jaune et l'onoclée sensible dresse sa fronde où c'est humide

lui avouer son ignorance 
10. les effets dans la voiture

cloisonnements

les sièges inclinés

contre ou selon le sens de la marche

petits groupes d'intimes formels

familles serres génétiques

sièges rouge-ébullition

par la lunette arrière

fuite perspective saccadée de traverses

s'effrayer de n'être en aucun lieu

que ce ventre de la propulsion

penser ailleurs

par exemple aux points fixes sous les masques 
11. bagages remis au porteur

la forme des ormes

leur solitude leurs bras dressés

signes assignés à la distance

maintenant lourde d'heures déroulées

sur les rubans d'acier

les charges

s'alignent réglementaires

poignées en attente de poigne

dessous la mère éveille l'enfant

à mots couverts

dehors les érables coulent 
12. du chapitre 291 de la Loi

un tiens vaut mieux

se contenter de verser

ses avoirs dans la fente des délais requis

pour être assuré des trajets les plus courts

entre deux points tout est compris

il y en aura bien d'autres

la suite suspendue

aux fils du télégraphe

maintenant désuète 
13. aucun agent n'a le pouvoir

les glaciers et les mers retraitent

quelques îles émergent quelques pics

d'immenses superficies sont découvertes

et deviennent d'un coup propices

les accidents se multiplient

dans les plissements des ères

les premiers échos (roulements

de tonnerre et d'éruptions

de vagues et d'averses cris

de bêtes et langages primitifs

chocs des outils contre la pierre

armes sonnées contre des armes

discours et rumeurs de machines

explosions sirènes et clameurs)

n'ont pas fini de se répandre

que les vestiges déjà

de ce monde agité

se dissolvent

quatre 